\title{
Health Action Process Approach (HAPA) as a Theoretical Framework to Understand Behavior Change
}

\author{
El Modelo Procesual de Acción en Salud como un marco de \\ referencia teórico para entender el cambio de conducta
}

\author{
Ralf Schwarzer ${ }^{1}$ \\ Freie Universität Berlin, Germany
}

\begin{abstract}
A theoretical framework to explain, predict, and modify health behaviors is presented which consists of various psychological constructs and a mediator mechanism. Risk perception, outcome expectancies, self-efficacy, intention, planning, and action control constitute the building blocks for a mediator model that is based on two processes: goal setting and goal pursuit. When it comes to the development of interventions to modify behaviors, one can target either the initial motivation phase or the subsequent volition phase. This is an open architecture framework allowing for various research designs and subsets of constructs. Hundreds of studies have been conducted based on this model. Three correlational and two intervention studies were chosen to illustrate the diversity of approaches targeting physical activity in Germany and Costa Rica, dental cleaning in India and Poland, and dust mask wearing in China. They differ in terms of the predictors that emerged as most relevant for behavior change.
\end{abstract}

Keywords. Outcome expectancies, self-efficacy, planning, action control, self-monitoring.

Resumen. Se presenta un marco de referencia para explicar, predecir, y modificar conductas de salud el cual consiste en varios constructos psicológicos y un mecanismo de mediación. La percepción de riesgo, las expectativas de resultado, la autoeficacia, la intención, y el control de acción constituyen los bloques de construcción para un modelo de mediación que está basado en dos procesos: el establecimiento de metas y la consecución de metas. Cuando se trata del desarrollo de intervenciones para modificar conductas, uno puede apuntar hacia la fase inicial de motivación, o bien, hacia la fase volitiva subsecuente. Este es un marco de referencia abierto, que permite varios diseños de investigación y un subconjunto de constructos. Se han realizado cientos de estudios basados en este modelo, de los cuales se escoge, como ilustración, tres estudios correlacionales y dos estudios de intervención, que abordan actividad física en Alemania y Costa Rica, higiene dental en India y Polonia, y uso de mascarillas contra el polvo en China. Estos difieren en términos de predictores que emergen como predictores más relevantes para el cambio de conductas.

Palabras Clave. expectativas de resultado, autoeficacia, planeamiento, control de la acción, auto-monitoreo.

\footnotetext{
${ }^{1}$ Ralf Schwarzer. Department of Health Psychology, Freie Universität Berlin, Germany. Postal Address: Habelschwerdter Allee 45, 14195 Berlin, Germany. E-mail: ralf.schwarzer@fu-berlin.de
} 


\section{Introduction}

Many health conditions are caused by risk behaviors, such as problem drinking, substance use, smoking, reckless driving, overeating, or unprotected sexual intercourse. The key question in health behavior research is how to predict and modify the adoption and maintenance of health behaviors. Fortunately, human beings have, in principle, control over their conduct. Health-compromising behaviors can be eliminated by self-regulatory efforts, and health-enhancing behaviors can be adopted instead, such as physical exercise, weight control, preventive nutrition, dental hygiene, condom or helmet use, screening, and vaccination. Health selfregulation refers to the motivational, volitional, and behavioral processes of abandoning risk behaviors in favor of adopting and maintaining health behaviors. In this article, theoretical constructs are presented, followed by a health behavior change model, and five study examples will serve as illustrations.

\section{Psychological Constructs}

Various theoretical constructs can be applied in health behavior research. In the following, six of them will be described: intention, risk perception, outcome expectancies, self-efficacy, planning, and self-monitoring.

Intention. Changes in health behaviors can be influenced by opportunities and barriers, sin by explicit decisions, or sin by random events. Here the discussion is constrained to intentional changes that happen when people become motivated to alter their previous way of life and set goals for a different course of action. For example, they may consider to quit smoking, or they make an effort to do so. Thus, intention represents a key factor in health behavior change. This construct had been suggested by Fishbein and Ajzen (1975) to operate as a mediator to overcome the attitude-behavior gap. Since behaviors could not be well predicted by attitudes, intention appeared to be a useful mediator and a better proximal predictor of many behaviors. Since then, there is consensus that intention is an indispensable variable when it comes to explaining and predicting behaviors. In the process of motivation, intention has been regarded as a kind of "watershed" between an initial goal setting phase and a subsequent goal pursuit phase.

Although the construct of intention is indispensable in explaining health behavior change, its predictive value is limited. When trying to translate intentions into behavior, individuals are faced with various obstacles, such as distractions, forgetting, or conflicting bad habits. Godin and Kok (1996), who reviewed 19 studies, found a mean correlation of .46 between intention and health behavior, such as exercise, screening attendance, and addictions. Abraham and Sheeran (2000) reported behavioral intention measures to account for 20$25 \%$ of the variance in health behavior measures. If not equipped with means to meet these obstacles, motivation alone does not suffice to change behavior. To overcome this limitation, further constructs are required that operate in concert with the intention.

Risk perception. Perceiving a health threat seems to be the most obvious prerequisite for the motivation to replace a risk behavior (Renner \& Schupp, 2011). If one is not aware at all of the risky nature of one's actions, motivation would hardly develop. Usually, people are aware of some level of risk although the accuracy of their perception may be biased. When it comes to a comparison with similar others, one's view of the risk is somewhat distorted ("Compared to others of my age and sex my risk of getting lung cancer is low/medium/ high"). This has become known as the 'optimistic bias'. Nevertheless, persons also acknowledge some degree of risk when confronted with objective data. There is a realistic component that keeps the positive illusions in leash. For example, smokers not only know that smoking can cause adverse health in others, they also perceive that they themselves are more at risk for lung cancer and other diseases than nonsmokers. Risk perception has two aspects: perceived severity of a health condition and personal vulnerability towards it. The first refers to the amount of harm that might occur, and the second pertains to the subjective probability that one could fall victim to that condition. Thus, it has been recommended that people should be informed about the existence of a health risk, and moreover, that they should imagine themselves as possible victims if 
they do not take the necessary precautions. Scaring people into health behaviors, however, has not been shown to be effective. In general, initial risk perception seems to be advantageous to put people on track for developing a motivation to change, but later on other variables are more influential in the self-regulation process, such as outcome expectancies, self-efficacy, and behavioral intentions. Risk perception in itself is insufficient to enable a person to change behavior. Rather, it may set the stage for a motivation process and further elaboration of thoughts about consequences and competencies.

Outcome expectancies. People not only need to be aware of the existence of a health threat, they also need to know how to regulate their behavior by understanding the contingencies between their actions and subsequent outcomes. These outcome expectancies are influential beliefs in the motivation to change (Bandura, 1997). A smoker may find more good reasons to quit than good reasons to continue smoking ('If I quit smoking then I will save money'). Similarly, positive outcome expectancies (e.g., "If I exercise five times per week, I will reduce my cardiovascular risk") are chiefly seen as being important in the motivation phase, when a person balances the pros and cons of certain behavioral outcomes. This imbalance does not lead directly to action but it can help to form an intention to quit. The pros and cons represent positive and negative outcome expectancies that are typical in rational decision making. However, such contingencies between actions and outcomes need not be explicitly worded and evaluated, they can also be rather diffuse mental representations, loaded with emotions.

Self-efficacy. Perceived self-efficacy portrays individuals' beliefs in their capabilities to exercise control over challenging demands and over their own functioning. Perceived self-efficacy has been found to be important at all stages in the health behavior change process (Bandura, 1997), but it does not always constitute exactly the same construct. Its meaning depends on the particular situation of individuals who may be more or less advanced in the change process. The rationale for the distinction between several phase-specific self-efficacy beliefs is that during the course of health behavior change, different tasks have to be mastered, and that different self-efficacy beliefs are required to master these tasks successfully. For example, a person might be confident in his or her capability to be physically active in general (i.e., high action self-efficacy), but might not be very confident to resume physical activity after a setback (i.e., low recovery self-efficacy). In the health action process approach (HAPA), three types of self-efficacy are distinguished: action self-efficacy, maintenance selfefficacy and recovery self-efficacy.

Action self-efficacy (also called preaction selfefficacy or task self-efficacy) refers to the first phase of the process, in which an individual does not yet act, but develops a motivation to do so. It is an optimistic belief during the preactional phase. Individuals high in action self-efficacy imagine success, anticipate potential outcomes of diverse strategies, and are more likely to initiate a new behavior. Those with less selfefficacy imagine failure, harbour self-doubts, and tend to procrastinate.

Maintenance self-efficacy (also called coping selfefficacy) represents optimistic beliefs about one's capability to cope with barriers that arise during the maintenance period. A new health behavior might turn out to be much more difficult to adhere to than expected, but a self-efficacious person responds confidently with better strategies, more effort, and prolonged persistence to overcome such hurdles. Once an action has been taken, individuals with high maintenance self-efficacy try harder and persist longer than those who are less self-efficacious.

Recovery self-efficacy addresses the experience of failure and recovery from setbacks. It pertains to one's conviction to get back on track after being derailed. The person trusts his/her competence to regain control after a setback or failure and to reduce harm.

This distinction between phase-specific self-efficacy beliefs has proven useful in various domains of behavior change. Action self-efficacy tends to predict intentions, whereas maintenance self-efficacy tends to 
predict behaviors. Phase-specific self-efficacy has also been found to differ in the effects on various preventive health behaviors, such as breast self-examination (Luszczynska and \& Schwarzer 2003), dietary behaviors (Schwarzer and \& Renner 2000) and physical exercise (Scholz, Sniehotta and \& Schwarzer 2005). For example, individuals who had recovered from a setback needed different self-beliefs than those who had maintained their levels of activity (Scholz et al. 2005).

Action Planning and Coping Planning. Intentions are more likely to be translated into behaviors when people anticipate detailed plans, imagine success scenarios, and develop preparatory strategies of tackling a challenging task (Schwarzer, 2016). Action plans and coping plans are based on contingencies with anticipated situations. An action plan such as "I plan to walk with my partner on Monday at 11 a.m. for an hour near the lake without pausing" includes situational cues and sufficient detail to qualify as a plan, going beyond a mere behavioral intention (such as "I intend to go for a walk twice a week") although there is a fluid transition between these two concepts. An action plan is sometimes called a When-WhereHow plan. The time of week and day and the presence of the partner constitute the cues that are supposed to trigger the action. Other cues can be stronger and more explicit such as "If I arrive at home after work today before 6 p.m, then I will immediately go walking in the park".

Both example items on physical activity above include uncertainty because the conditions for performing the action might be unfavorable, preventing the person from actually executing the plan. This could be bad weather, physical discomfort, a traffic jam, a visiting friend etc. To account for such barriers, the concept of coping planning has been developed (Scholz et al., 2008, ; Sniehotta et al, 2005; see meta-analyses by Carraro, \& Gaudreau, 2013; Kwasnicka, Presseau, White, \& Sniehotta, 2013). Coping plans serve a compensatory function. After one's first-choice plan becomes unrealistic due to anticipated obstacles or better options to attain one's goal, coping plans could be activated that were put in reserve beforehand. Such plans represent an alternative to the initial action plan in terms of the target behavior (e.g., rather swimming instead of walking), the time (e.g., rather Tuesday morning), the social situation (e.g., with a friend instead of aspouse), and other circumstances. Coping plans can be hierarchically structured containing sequential cues with several alternative responses. An example is: "If I feel exhausted of studying, then I will go to the kitchen and prepare a coffee; however, if it is already after 5 p.m. (and I would risk not falling sleep), I rather go out for a refreshing walk; but if it is raining, then I play the guitar to maximize goal attainment of studying for the exam, etc". Psychological interventions have been found useful to ask clients to produce a number of well elaborated coping plans to make goal attainment more likely. This pertains to clients who are able to forecast possible scenarios as well as obstacles and opportunities, and who are capable to understand the contingencies. People need to imagine vivid scenarios that prevent them from performing their intended action, and they need to form one or more coping plans to prepare for difficult or facilitating situations.

Coping planning is supposed to be a more effective self-regulatory strategy than mere action planning. After people form an action plan, they imagine possible obstacles and generate coping strategies. Thus, coping planning comes on top of action planning, and their separate effects are often hard to disentangle. There is more convergent than discriminant validity of these two concepts, but keeping them distinct is useful for the design of interventions.

Action planning and coping planning are alterable variables. They can be easily communicated to individuals with self-regulatory deficits which is the reason why they have been frequently applied in interventions to change health behaviors. Many studies have documented the evidence of successful planning interventions (for a review see Hagger, \& Luszczynska, 2014).

Self-monitoring (action control). Self-monitoring is the key component of action control. While planning is a prospective strategy, that is, behavioral plans are made before the situation is encountered, action control is a 
concurrent self-regulatory strategy, where the ongoing behavior is continuously evaluated with regard to a behavioral standard (Sniehotta et al., Nagy, Scholz, \& Schwarzer, 2006). Action control can comprise three facets: self-monitoring ("I consistently monitored when, where, and how long I exercise"), awareness of standards ("I have always been aware of my prescribed training programme"), and self-regulatory effort ("I took care to practice as much as I intended to").

\section{Mechanisms: A self-regulation framework.}

It is useful to distinguish phases of self-regulation and allocate persons in terms of their individual position within these phases. A useful distinction is the one between motivation and volition. In the motivation phase, individuals are in a deliberative mindset while setting a goal (intention), whereas in the volitional phase, they are in an implementation mindset while pursuing their goal. The psychological constructs are more or less important for either goal setting or goal pursuit. Therefore, they can be assigned to these two phases as in table 1.

In the following, a process model is described that covers the goal setting as well as the goal striving phase of health self-regulation, called the health action

Table 1

Psychological constructs according to phases of behavior change

\begin{tabular}{ll}
\hline $\begin{array}{l}\text { Motivation Phase } \\
\text { (Goal setting) }\end{array}$ & Volition Phase \\
& (Goal pursuit) \\
\hline
\end{tabular}

Risk Perception

Outcome Expectancies

Action Self-Efficacy

Intention

Coping Self-Efficacy
Recovery Self-Efficacy
Action Planning
Coping Planning
Self-monitoring (action
control)

process approach (HAPA; Schwarzer, 1992, 2008). Other social-cognitive models have been criticized mainly because of the so-called intention-behavior gap (referring to the frequent failure of intention to predict behavior). As a comprehensive self-regulation model, HAPA suggests a distinction between preintentional motivation processes that lead to a behavioral intention, and postintentional volition processes that lead to actual behavior (figure 1). Before changing their habits, people need to become motivated. This is seen as a process towards an explicit goal or intention (e.g., 'I intend to quit smoking this week'). Three constructs are considered to play a major role in this process: (a) risk perception, (b) outcome expectancies, and (c) self-beliefs. Actually changing one's health behavior is considered to be a challenging self-regulation process. After people have become committed to a goal they need to prepare action and, later, maintain the changes in the face of barriers and setbacks. Thus, goal setting and goal pursuit can be understood as two distinct processes that require self-regulatory effort. After forming an intention, the volitional phase is entered. When a person is inclined to adopt a particular health behavior, the 'good intention' has to be transformed into detailed instructions on how to perform the desired action. Once an action has been initiated, it has to be maintained. This involves self-regulatory beliefs, skills, and strategies such as planning, coping self-efficacy, and recovery self-efficacy. Additional volitional constructs, often included in HAPA research, are action control (self-monitoring) and social support that may shield one's goal pursuit from distracting or tempting situations (Schwarzer, 2015).

The volitional process can be subdivided into sequences such as planning, initiation, maintenance, and relapse management. The adoption and maintenance of the health action is not achieved through an act of will but involves the development of self-regulatory skills and strategies. This embraces various means to influence one's own motivation and behaviors such as the setting of attainable, proximal subgoals, creating incentives, drawing from an array of coping options, monitoring progress, and mobilizing social support. Plans specify the when, where, and how 


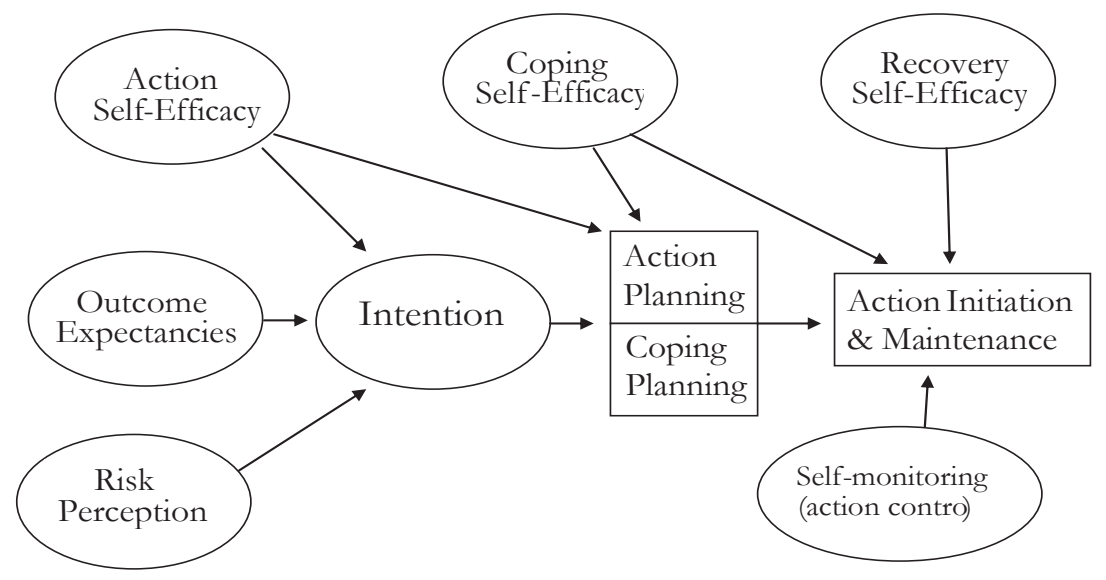

Figure 1. Health action process approach (Schwarzer, 1992, 2008).

of a desired action, and the individuals take initiative when the critical situation arises, and sin they invest in preparatory behaviors. Action control includes focusing one's attention on the task at hand, while avoiding attention to distractors, resisting temptations, and managing negative emotions. Perceived selfefficacy is required to overcome obstacles and to stimulate self-motivation repeatedly. Once an action has been taken, persons with high maintenance selfefficacy invest more effort and persist longer than those who are less self-efficacious.

Competent relapse management is needed to recover from setbacks. Some people rapidly abandon their newly adopted behavior when they fail to get immediate results. When facing high-risk situations (e.g., a location where others drink alcohol), they may not resist due to a lack of self-efficacy. The competence to recover is different from the competence to initiate an action. Restoration, harm reduction, and renewal of motivation are serviceable strategies within the process of health behavior change.

The purpose of the mediator model described so far (figure 1) is twofold: It allows a prediction of behavior, and it explains the assumed causal mechanism of behavior change. Research that is based on this model, therefore, employs path-analytic methods. There are a host of empirical studies that have applied the HAPA and confirmed its usefulness (for an overview, see Schwarzer \& Luszczynska, 2015). There is not always a perfect match between the model and the real-world applications. Due to a variation in research questions and contextual constraints, there are often more parsimonious versions of the HAPA aiming at the examination of only certain aspects of the model. In some cases, for example, there has been no sufficient discriminant validity between action planning and coping planning, so it was preferred to collapse these two facets into one construct of planning (Zhou,Gan, Ke, Knoll, Lonsdale, \& Schwarzer, 2016). In other cases, there has been no sufficient discriminant validity between coping self-efficacy and recovery selfefficacy, and therefore, both were lumped together to a construct labeled volitional self-efficacy (Craciun, Schüz, Lippke, \& Schwarzer, 2012).

\section{Empirical illustrations of behavior change: Mediator designs}

HAPA is not an easily testable theory that can be falsified by data. Rather, it is an open architecture framework that serves to guide research and practice. Therefore, studies vary in the number and type of constructs that they employ. Also, some studies choose a narrow window of the model, for example, by looking at the volitional side when addressing a sample of 
individuals who are already sufficiently motivated for behavioral change. In the following, three correlational studies are presented as an illustration of the diversity of research approaches.

Adherence to dust mask wearing in Chinese citizen. Adherence to the use of filtering facemask respirators on hazy days to reduce exposure to air pollution was examined (Zhou et al., 2016). In a longitudinal survey, 164 young adults from Beijing, China, completed assessments at baseline (Time 1), at two weeks (Time 2), and again four weeks later (Time 3). Self-efficacy, risk perception, and outcome expectancies were measured along with intention at Time 1, planning and action control at Time 2, and facemask use at Time 3. Self-efficacy and risk perception jointly predicted behavioral intention at Time 1. Planning and action control at Time 2 jointly predicted behavior at Time 3 , serving as parallel mediators between intention (Time 1) and facemask use (Time 3). Results support theorybased psychological mechanisms, with a focus on risk perception at the first stage, and planning and action control at the second stage. These mechanisms might be influential in the adoption and maintenance of selfprotective facemask wearing (figure 2).

Physical Activity among Overweight German Adults. A study tested the applicability of the HAPA in a sample of obese German adults in the context of physical activity. Physical activity was assessed along with motivational and volitional variables (motivational self-efficacy, outcome expectancies, risk perception, intention, maintenance self-efficacy, action planning, coping planning, recovery self-efficacy, social support) in a sample of 484 obese men and women (body mass index $\geq 30 \mathrm{~kg} / \mathrm{m}^{2}$ ). Motivational self-efficacy, outcome expectancies, and social support were related to intention. An association between maintenance self-efficacy and coping planning was found. Recovery self-efficacy and social support were associated with physical activity. No relationships were found between risk perception and intention, and between planning and physical activity. The assumptions derived from the HAPA were partly confirmed although the main limitation of this study was its cross-sectional research design (Parschau, Barz, Richert, Knoll, Lippke, \& Schwarzer, 2014). Instead of self-monitoring, social support had been included in this study with significant links to motivation and behavior.

Physical Exercise in Costa Rican Students. In another study, conducted in 487 young adults in Costa Rica, the aim was to examine in particular action control which is supposed to mediate between planning and exercise (Reyes Fernandez, Fleig, Godinho, MontenegroMontenegro, Knoll, \& Schwarzer, 2015). Behavioral intention, action planning, coping planning, and past behavior were assessed at baseline, and action control

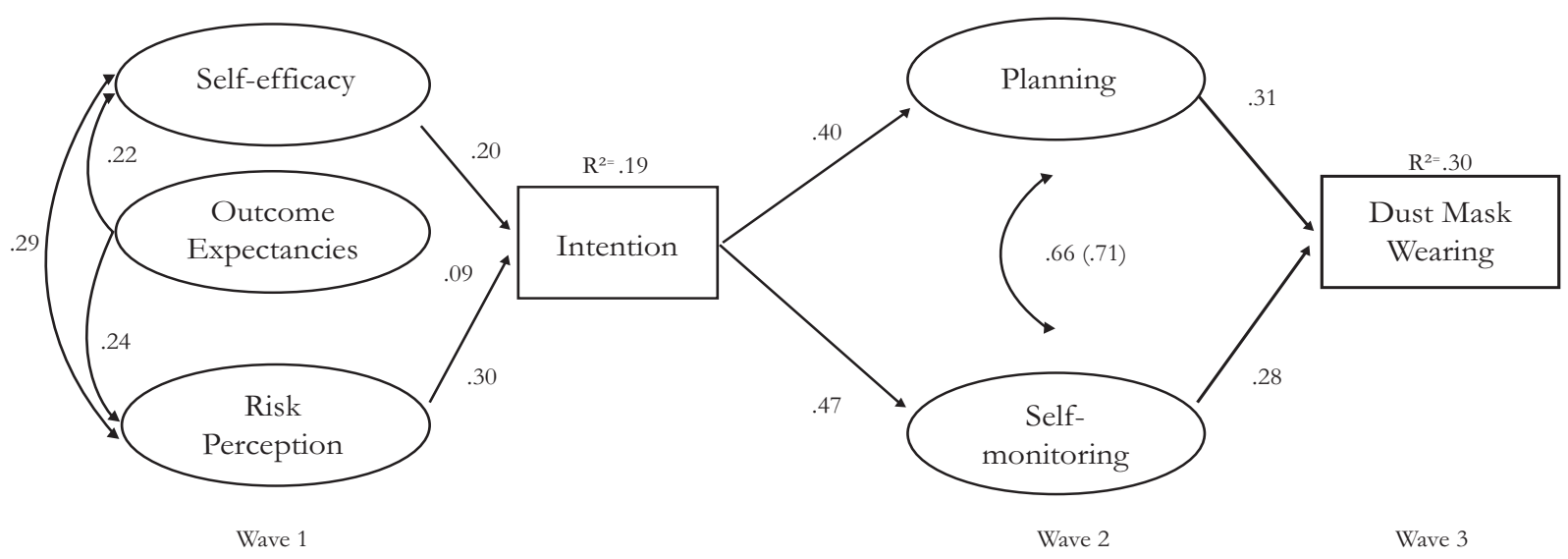

Figure 2. HAPA application in the context of dust mask use (Zhou et al., 2016). 


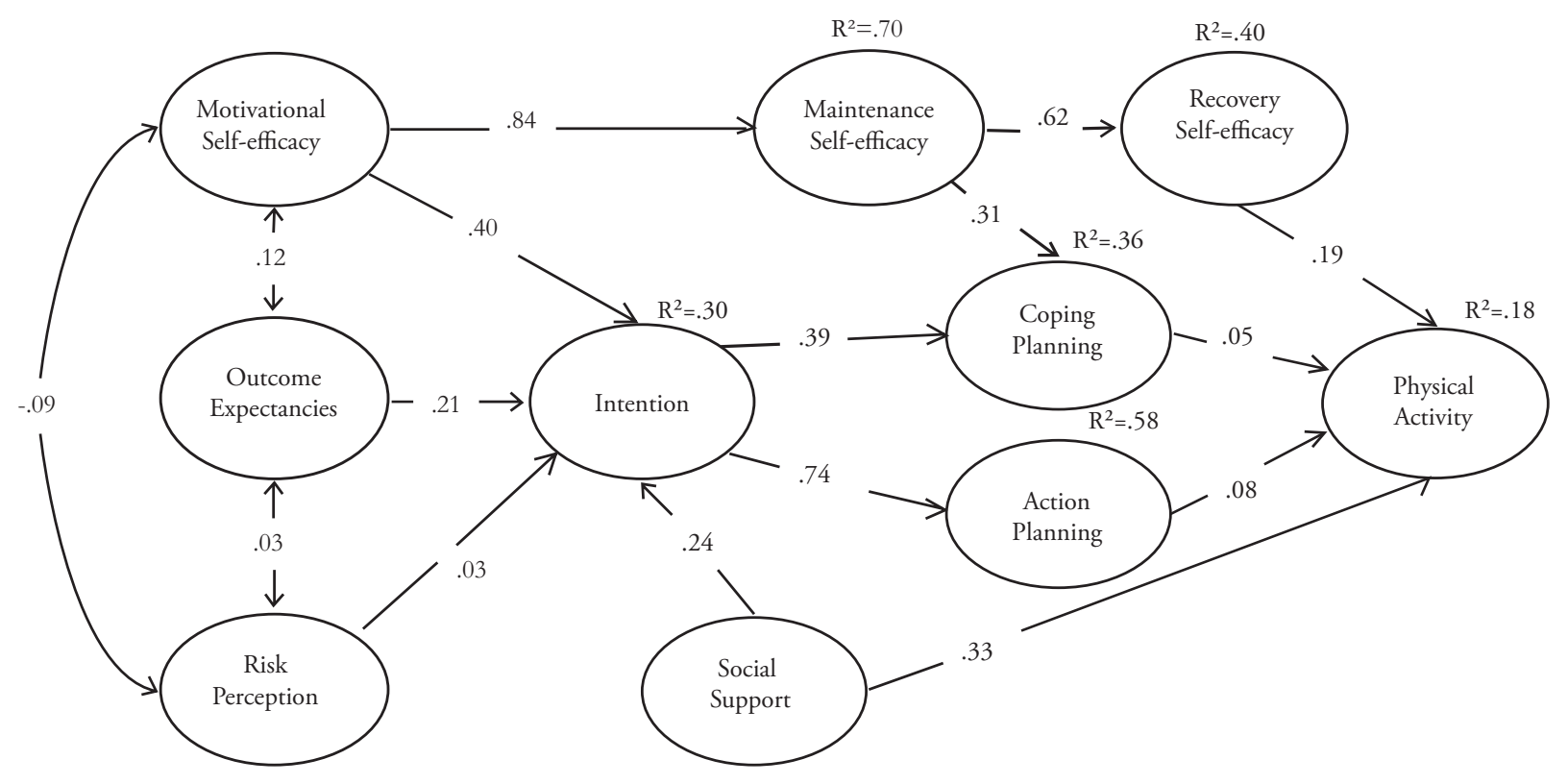

Figure 3. Physical Activity among Adults with Obesity (Parschau et al., 2014). All parameters are significantly positive. Standardized solution.

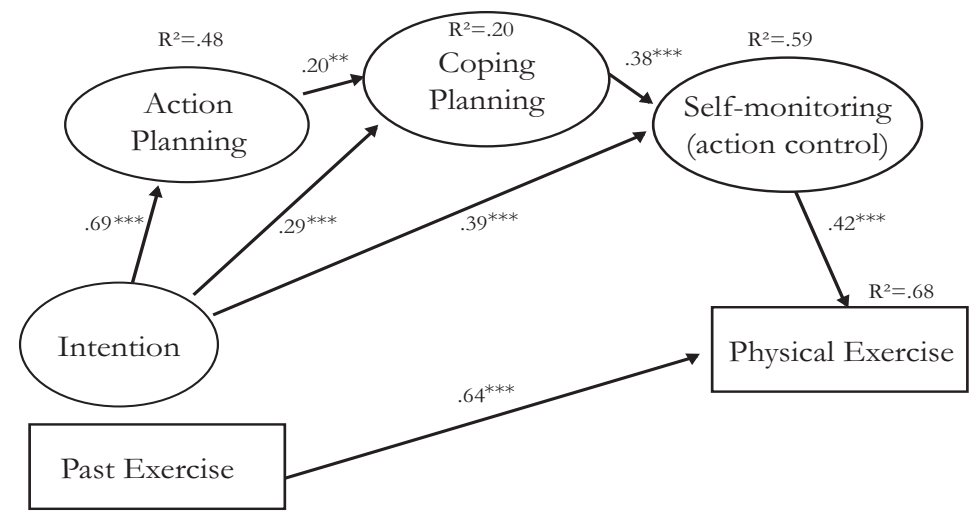

Figure 4. Physical Exercise in Costa Rican Students (Reyes Fernandez et al., 2015). Standardized solution $* * p<.01 ; * * * p<.001$

were sequential mediators between intentions and later physical exercise levels. Action and coping planning were not directly related to exercise, but indirectly via action control. These findings support the assumption of a sequential mediation for planning and action control as antecedents of physical exercise. Action control is needed for exercise because planning in itself is not always sufficient. Maintaining exercise levels may be attributed to effective self-regulatory strategies such as action control in combination with planning. 


\section{Theory-based interventions}

There are a large number of intervention studies more or less explicitly derived from HAPA (for an overview see Schwarzer \& Luszczynska, 2015). If an article reports a combination of coping planning, recovery self-efficacy (or coping/maintenance selfefficacy), and action control (or self-monitoring), mediating between intervention and behavioral outcome, then it can be considered a HAPA study, even if this model or its source is not explicitly mentioned. In other cases, where fewer of these constructs are investigated (e.g., only planning and self-efficacy as mediators), it may not be clear whether the study has been derived from HAPA or not. As HAPA is an open-architecture framework, it also tends to inspire research that is not necessarily in line with the original model. In many cases the published reports address only a narrow aspect that is in line with specific research questions, not providing a full account of the entire model that had informed the study.

HAPA-Interventions can be stage-matched, meaning that different subgroups of persons receive different treatments, tailored to their mindsets, or interventions can be complex, meaning that all get the same treatment that includes a number of ingredients from the theory. The most often used research design is the two-arm randomized trial in which one group receives a motivational treatment whereas the other one receives a volitional treatment. The motivational treatment (also called: educational treatment) has a focus on action self-efficacy, outcome expectancies, and risk communication sin ) whereas the volitional treatment (also called: self-regulatory treatment) has its focus on coping self-efficacy, planning, and action control. If no stage-matching occurs, then one can expect better effects of the volitional treatment on the target behavior because those constructs are more proximal to behavior and include tangible skills (planning, self-monitoring) that enhance the initiation and maintenance of the chosen target behavior.

In the following, two examples from dental flossing promotion are mentioned that have used a HAPAbased intervention but report only empirical results on few outcomes because the other constructs turned out to be redundant in the statistical analyses. Thus, one has to distinguish between the theory that has informed the intervention sin coma and the analytic model that contains a subset with the most relevant results. It is notable that both interventions have been successful but differ in terms of their mediation chains.

\section{Self-management Cues to Promote Interdental Cleaning among Indian Dental Outpatients}

A study sought to examine whether a brief oral health promotion program (self-management cues that were based on self-efficacy and self-regulatory skills) in combination with an incentive (free dental treatment) would make a difference in the adoption of regular dental flossing in Indian periodontal outpatients (Lhakhang et al., 2016). One hundred and twelve participants $(n=$ 55 oral health promotion intervention group; $n=57$ control group) were assigned to the intervention (selfmanagement cues + incentive) or control groups, and follow-up assessments were performed three weeks later. Flossing frequency, behavioral intentions, and perceived self-efficacy served as dependent variables. The intervention yielded effects on flossing frequency $(p<.01)$ and flossing intentions $(p<.01)$ at follow-up. By path analysis a sequential mediation chain demonstrated an indirect effect of the intervention on flossing via self-efficacy and intentions: the intervention predicted changes in self-efficacy which, in turn, were associated with changes in intentions, predicting flossing frequency at follow up, while controlling for baseline behavior, gender, and age (figure 5, upper panel). The intervention has been found effective in improving interdental cleaning motivation and habits in periodontal patients, and the facilitating role of dental self-efficacy has been demonstrated. All the other HAPA constructs that were included in the complex intervention package sin coma did not show any relevant relationships in the final statistical model serving to explain the target behavior.

\section{Self-management Cues to Promote Interdental Cleaning among Polish Students}

An oral health intervention guided by HAPA among 287 Polish university students, aged 19 to 26 
years, compared an intervention group that received a brief self-regulatory treatment, with a passive and an active control group (Schwarzer, Antoniuk, \& Gholami, 2015). Dental flossing, self-efficacy, and selfmonitoring were assessed at baseline, and three weeks later the intervention led to an increase in dental flossing regardless of experimental condition. However, treatment-specific gains were documented for selfefficacy and self-monitoring. Moreover, changes in the latter two served as sequential mediators in a path model, linking the intervention with subsequent dental flossing and yielding significant indirect effects. Selfefficacy and self-monitoring played a mediating role in facilitating dental flossing (figure 5, lower panel). All the other HAPA constructs that were included in the complex intervention package sin coma did not show any relevant relationships in the final statistical model serving to explain the target behavior. Espacio Interventions that aim at an improvement of oral selfcare should consider using volitional constructs.

\section{Conclusions}

This article has described various psychological constructs such as intention, risk perception, outcome expectancies, self-efficacy, planning, and self-monitoring. None of them itself constitutes a "magic bullet" for behavior change. They need to operate in concert, and that is why theories and models are needed to better understand the mechanisms of diverse health behavior change processes. Health behavior change is associated with changes in self-beliefs and self-regulatory skills. Various process models and psychological constructs
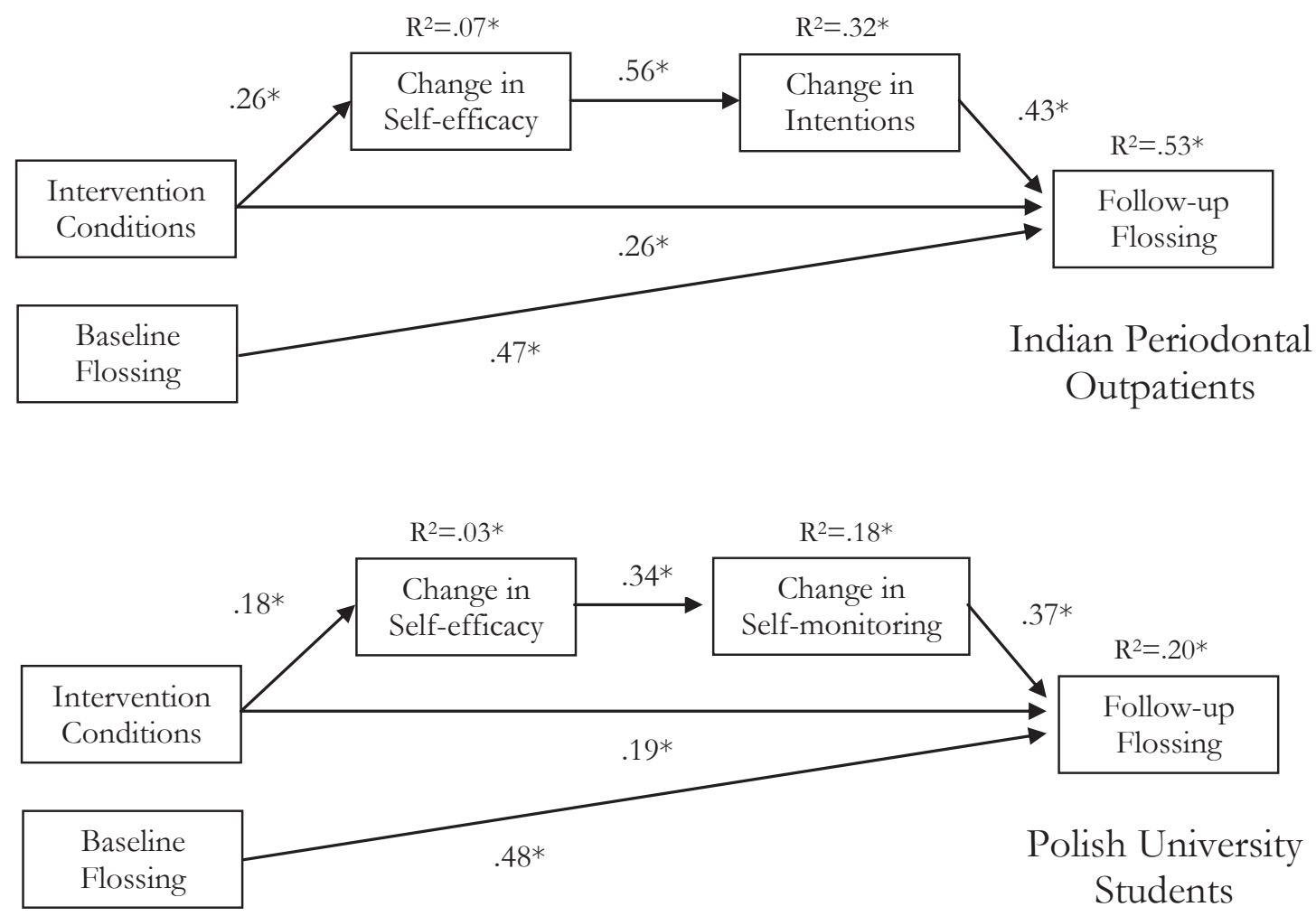

Figure 5. Oral health intervention studies in Indian periodontal outpatients (upper panel) and in Polish university students (lower panel) focusing on different sequential mediation chains. $p<.05 ;{ }^{* *} p<.01$. Standardized solution. 
have been employed to shed light on the antecedents and consequences of personal attempts to make a difference in one's life. They describe control processes that drive the adoption and maintenance of healthenhancing behaviors as well as the liberation from addictive or health-compromising behaviors.

The main limitation of this and most other health behavior models can be identified as a lack of explicit consideration of non-conscious processes. People are often unaware of their emotional barriers and temptations that guide their actions, and socialcognitive approaches to change their behaviors are often futile. An explicit dual-process model that deals with both levels of conscious and unconscious factors has been recently presented by Borland (2014).

Nevertheless, HAPA is becoming more appealing to health psychologists, after a great deal of research in the last decades has underscored the validity of its assumptions. Cumulative evidence shows that the shift from rather static motivation and attitude variables to more dynamic self-regulatory variables such as coping planning, maintenance self-efficacy, and action control is a promising step towards a better understanding of health behavior change. The strength of the model lies in its focus on mediating mechanisms involving several volitional constructs.

\section{References}

Abraham, C., \& Sheeran, P. (2000). Understanding and changing health behaviour: From health beliefs to self-regulation. In P. Norman, C. Abraham, \& M. Conner (Eds.), Understanding and changing health behaviour (pp. 3-24). Amsterdam: Harwood.

Bandura, A. (1997). Self-efficacy: The exercise of control. New York: Freeman.

Borland, R. (2014). Understanding Hard to Maintain Behaviour Change: A Dual Process Approach, Chichester: Wiley

Carraro, N., \& Gaudreau, P. (2013). Spontaneous and experimentally induced action planning and coping planning for physical activity: A meta-analysis.
Psychology of Sport and Exercise, 14(2), 228-248. doi: 10.1016/j.psychsport.2012.10.004

Craciun, C., Schüz, N., Lippke, S., \& Schwarzer, R. (2012). A mediator model of sunscreen use: A longitudinal analysis of social-cognitive predictors and mediators. International Journal of Behavioral Medicine, 19(1), 65-72. doi: 10.1007/s12529-0119153-x

Fishbein, M., \& Ajzen, I. (1975). Belief, attitude, intention, and behavior: An introduction to theory and research. Reading, MA: Addison-Wesley.

Godin, G., \& Kok, G. (1996). The theory of planned behavior: A review of its applications to healthrelated behaviors. American Journal of Health Promotion, 11(2), 87-97.

Hagger, M. S., \& Luszczynska, A. (2014). Implementation intention and action planning interventions in health contexts: State of the research and proposals for the way forward. Applied Psychology: Health and Well-Being, 6(1), 1-47. doi: 10.1111/aphw.12017

Kwasnicka, D., Presseau, J., White, M., \& Sniehotta, F. F. (2013). Does planning how to cope with anticipated barriers facilitate health-related behaviour change? A systematic review. Health Psychology Review, 7(2), 129-145. doi: 10.1080/17437199.2013.766832

Lhakhang, P., Hamilton, K., Sud, N., Sud, S., Kroon, J., Knoll, N., \& Schwarzer, R. (2016). Combining Self-management Cues with Incentives to Promote Interdental Cleaning among Indian Periodontal Disease Outpatients. BMC Oral Health. doi: 10.1186/s12903-016-0164-5

Luszczynska, A., \& Schwarzer, R. (2003). Planning and self-efficacy in the adoption and maintenance of breast self-examination: A longitudinal study on self-regulatory cognitions. Psychology and Health, 18(1), 93-108. doi: 10.1080/0887044021000019358

Parschau, L., Barz, M., Richert, J., Knoll, N., Lippke, S., \& Schwarzer, R. (2014). Physical Activity among Adults with Obesity: Testing the Health Action 
Process Approach. Rehabilitation Psychology, 59(1), 42-49. doi: 10.1037/a0035290

Renner, B., \& Schupp, H. (2011). The perception of health risks. In H. Friedman (Ed.). The Oxford handbook of health psychology (pp. 639-666). New York: Oxford University Press.

Reyes Fernández, B., Fleig, L., Godinho, C. A., Montenegro-Montenegro, E., Knoll, N., \& Schwarzer, R. (2015). Action control bridges the planning-behavior gap: A longitudinal study on physical exercise in young adults. Psychology \& Health, 30(8), 911 - 923 . DOI: 10.1080/08870446.2015.1006222

Scholz, U., Schüz, B., Ziegelmann, J.P., Lippke, S., \& Schwarzer, R. (2008). Beyond behavioural intentions: planning mediates between intentions and physical activity. British Journal of Health Psychology 13(3),479-494. http://dx.doi. org/10.1348/135910707X216062

Scholz, U., Sniehotta, F. F., \& Schwarzer, R. (2005). Predicting physical exercise in cardiac rehabilitation: The role of phase-specific self-efficacy beliefs. Journal of Sport and Exercise Psychology, 27(2), 135-151.

Schwarzer, R. (1992). Self-efficacy in the adoption and maintenance of health behaviors: Theoretical approaches and a new model. In R. Schwarzer (Ed.), Self-efficacy: Thought control of action (pp. 217-243). Washington, DC: Hemisphere.

Schwarzer, R. (2008). Modeling health behavior change: How to predict and modify the adoption and maintenance of health behaviors. Applied Psychology: An International Review, 57(1), 1-29. doi: 10.1111/j.1464-0597.2007.00325.x

Schwarzer, R. (2015). Health self-regulation, motivational and volitional aspects of. In J. D. Wright (Editor-in-chief), International encyclopedia of the social \& behavioral sciences (2nd ed., Vol. 10., pp. 710-715). Oxford: Elsevier.

Schwarzer, R. (2016). Coping planning as an intervention component: A commentary. Psychology \& health, 1-4.

Schwarzer, R., Antoniuk, A., \& Gholami, M. (2015). A brief intervention changing oral self-care, selfefficacy, and self-monitoring. British Journal of Health Psychology, 20(1), 56-67. doi: 10.1111/ bjhp.12091

Schwarzer, R., \& Luszczynska, A. (2015). Health Action Process Approach. In M. Conner, \& P. Norman (Eds.), Predicting health behaviours (pp.252-278). 3rd edition. Maidenhead, UK: McGraw Hill Open University Press.

Schwarzer, R., \& Renner, B. (2000). Social-cognitive predictors of health behavior: Action self-efficacy and coping self-efficacy. Health Psychology, 19, 487-495.

Sniehotta, F. F., Nagy, G., Scholz, U., \& Schwarzer, R. (2006). The role of action control in implementing intentions during the first weeks of behaviour change. British Journal of Social Psychology, 45(1), 87-106.

Sniehotta, F. F., Schwarzer, R., Scholz, U., \& Schüz, B. (2005). Action planning and coping planning for long-term lifestyle change: Theory and assessment. European Journal of Social Psychology, 35(4), 565576. doi: 10.1002/ejsp.258

Zhou, G., Gan, Y., Ke, Q., Knoll, N., Lonsdale, C., \& Schwarzer, R. (2016). Avoiding exposure to air pollution by using filtering facemask respirators: An application of the Health Action Process Approach. Health Psychology, 35(2), 141-147. doi: 10.1037/ hea0000264

Received: April $7^{\text {th }} 2016$

Accepted: September $9^{\text {th }} 2016$ 